\title{
Smokeless Tobacco and Its III-Effects: Recent Literature Update
}

\author{
Hitesh R. Singhavi $^{10}$ Arjun Singh ${ }^{2,3(0)}$ Pankaj Chaturvedi 2,3 \\ ${ }^{1}$ Department of Surgical Oncology, Fortis Hospital, Mulund, Mumbai, \\ Maharashtra, India \\ 2 Department of Head and Neck Services, Tata Memorial Hospital, \\ Tata Memorial Centre, Mumbai, Maharashtra, India \\ ${ }^{3}$ Department of Surgical Oncology, Homi Bhabha National Institute, \\ Mumbai, Maharashtra, India \\ Address for correspondence Pankaj Chaturvedi, MS, 1227, Homi \\ Bhabha Block, Tata Memorial Hospital, Mumbai, Maharashtra, India \\ (e-mail: chaturvedi.pankaj@gmail.com). \\ Ind J Med Paediatr Oncol 2021;42:486-490.
}

\begin{abstract}
According to the Global Adult Tobacco Survey part 2 (GATS-2), approximately 200 million adult Indians consume smokeless tobacco (SLT). Circumvention of SLT product ban has been observed. We conducted a review of the literature to summarize the ill effects of tobacco for the articles published from 2019 to 2020. A systematic search of the databases PubMed (2019 onward) and Web of Science (2019 onward), through February 2021 was done. Search yielded 1,061 articles and after excluding articles

Keywords

- smokeless tobacco

- gutkha

- oral cancer

- cancer based on the inclusion criteria, 37 articles were taken in to consideration. The review shows that differential SLT product has specific odds of oral carcinogenesis. Review also indicates the emerging data of cardiovascular risk due to higher use of SLT products along with its known cause of oral cancer. It also cautions about the adverse consequences of pregnancy associated with SLT use.
\end{abstract}

\section{Smokeless Tobacco and Its III Effects: Recent Literature Update}

Oral cavity cancers are among the most common cancers affecting males in India. ${ }^{1}$ Tobacco, alcohol, and areca nut are the root causes for high incidence of oral cancer in India. ${ }^{2}$ However, tobacco has widespread effects on oral health, apart from oral cavity cancers, it is also responsible for 7 million deaths worldwide. ${ }^{3}$ Smokeless tobacco not only causes cancer of the oral cavity, it is also responsible for higher incidence of esophageal and pancreatic cancers. ${ }^{4}$ It has been documented to increase the risk of stroke and cardiovascular diseases. Consumption of smokeless tobacco (SLT) during pregnancy can also lead to higher chances of reduced gestation age and birth weight. $^{5}$
According to the Global Adult Tobacco Survey part 2 (GATS-2) India survey, ${ }^{6}$ incidence of SLT use is significantly more than combustible tobacco product. It has also shown that in India, states like Madhya Pradesh, Odisha, Bihar, Jharkhand, Chhattisgarh, and Northwestern states have high incidence of SLT use (above 30\%) while Maharashtra, Gujrat, and Uttar Pradesh fall in moderate category (20-30\%) and North and South Indian states have incidence of SLT use ranging from 10 to $20 \%$. More than 30 types of SLT are consumed in India. To curb its usage and production, government has enacted many tobacco control legislations. As of May 2013, few SLT product involving pan masala and gutkha are banned in 24 states and 3 union territories in India. ${ }^{7}$ However, the Federal Food Safety and Regulation act 2011 allows harmful product to be banned for a year after which it needs to be renewed every year based on the current

(C) 2021. Indian Society of Medical and Paediatric Oncology. All rights reserved.

This is an open access article published by Thieme under the terms of the Creative Commons Attribution-NonDerivative-NonCommercial-License, permitting copying and reproduction so long as the original work is given appropriate credit. Contents may not be used for commercial purposes, or adapted, remixed, transformed or built upon. (https://creativecommons.org/ licenses/by-nc-nd/4.0/)

Thieme Medical and Scientific Publishers Pvt. Ltd., A-12, 2nd Floor, Sector 2, Noida-201301 UP, India 
evidence. Thus, primary aim of the study was to update the literature with the latest available evidence on the ill effect of SLT in India, as well as globally.

\section{Methods}

A systematic search of the databases PubMed (2019 onward) and Web of Science (2019 onward) through February 2021 was done. Relevant articles were identified. The search terms used were "smokeless tobacco," "cancer," "oral cancer," "ill effects," "cardiovascular disease," “stroke,” "pregnancy,” “potentially malignant lesion," "precancer," "gutkha," and "gutka." These were searched as text, as well as in combination using Boolean "AND." The cross-reference lists of relevant articles were also screened for suitable studies. This search yielded 1,061 articles. Inclusion criteria involved those articles which were published between the year 2019 and 2021, those published in English literature, studies including exposed individuals consuming SLT leading to oral cancer or cancer or any ill-health effects were included in the review. Articles were excluded from the review if they failed to describe the factors of interest of the study. Search strategy is described in - Fig. 1. Among these articles, 37 articles were included in the narrative review which described SLT and its ill effects on health. - Table 1 presents the recent studies showing relationship between SLT use and oral cancer/cardiovascular diseases.

\section{Recent Literature Updates}

\section{Smokeless Tobacco and Cancer: Clinical Studies}

India is one of the largest producers and the highest consumer of SLT product. Approximately, 20 crore Indians consume SLT. ${ }^{4}$ Thus, India has the highest population of new oral cancer cases every year. Last year, a global systematic review was published to find an association of SLT use and oral cancer. ${ }^{8}$ This study consisted of 37 studies all over the world with majority being from the South East Asian Region (SEAR). For this region, there was significantly higher risk (4.44 times) of oral cancer associated with SLT. Surprisingly, in this study, females had significantly higher risk of oral cancer. This study also looked at product-wise vulnerability to oral cancer. Gutkha has the highest odds of carcinogenesis to the scale of $860 \%$ more than the rest. Similarly, oral snuff (four times) also had higher odds to cause cancer. Another systematic review by Asthana et al analyzed 12 systematic review that found a strong association between SLT and oral cancer. ${ }^{9}$ All type of SLT had association in causation of oral cancer but gutkha and pan masala had higher odds for it. An African and Middle East based systematic analysis reviewed six studies and found shammah (form of SLT) had higher odds (39 times) of developing oral cancer. ${ }^{10}$ Global burden analysis of SLT was performed for 127 countries including India. ${ }^{11}$ This study pointed out that South Asian Region (India accounting for $70 \%$ of the load) is plagued with SLT pandemic with the highest mortality rate. At least 2.5 million disability adjusted life years (DALYs) were lost in the year due to cancer associated with SLT. A case control prospective study aimed to evaluate the risk of oral

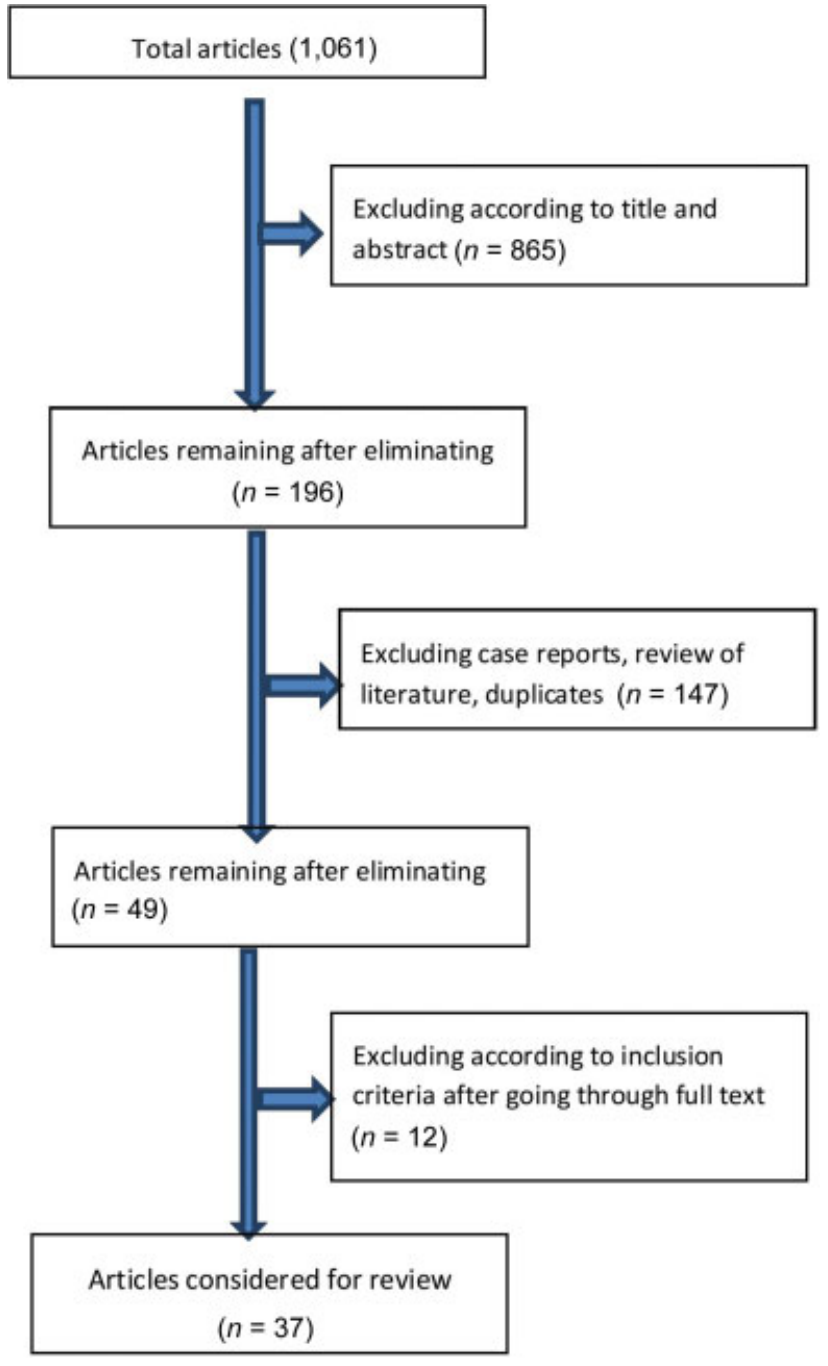

Fig. 1 A flowchart depicting the study selection.

cavity cancers among SLT users. This study enrolled oral cancer patients as cases and their attendants were enrolled as controls. It concluded that type, frequency, and duration of tobacco use were significantly high in cases as compared with controls. Individuals who ever consumed SLT product had an odds ratio of 4.98 (95\% confidence interval [CI]: 2.769.01) while even when adjusting for smoking and age, snuff users were 4.6 times more vulnerable to oral cancers. ${ }^{12}$

A cross-sectional study conducted in Nepal consisting of 851 patients concluded high incidence of oral cancer (55.5\%), premalignant lesion (12\%), and the majority of them were SLT users. ${ }^{13}$ This could be attributed to high incidence of SLT use in Nepal where one-third of the males (more than 30\%) use SLT, betel quid with tobacco being the most common. ${ }^{14}$ However, the study is subject to selection bias. Another study conducted among rural Indian population studied the pattern of tobacco use in oral cancer patients. ${ }^{15}$ It was observed that more than $40 \%$ of all the rural Indian population consume SLT. Three-fourths of all the head and neck cancer patient enrolled in the study consumed SLT, while approximately $10 \%$ of all the tobacco chewers were independent users of gutkha. 
Table 1 Studies presenting the relationship between smokeless tobacco and oral cancer/cardiovascular diseases

\begin{tabular}{|c|c|c|c|c|c|c|c|c|}
\hline $\begin{array}{l}\text { SI. } \\
\text { no. }\end{array}$ & Author & Study type & Site & Outcome & $\begin{array}{l}\text { Type of } \\
\text { SLT }\end{array}$ & OR & $\mathrm{HR}$ & $\mathrm{Cl}(95 \%)$ \\
\hline 1 & Khan et al ${ }^{16}$ & Case-control & India & OSMF & SLT & 18 & - & NA \\
\hline 2 & Khan et al ${ }^{16}$ & Case-control & India & OSMF & Gutkha + bidi & 12.3 & - & NA \\
\hline 3 & Patil et al ${ }^{10}$ & $\begin{array}{l}\text { Systematic } \\
\text { review }\end{array}$ & Africa & $\begin{array}{l}\text { Oral cancer/ } \\
\text { OPMD }\end{array}$ & Shammah & - & 38.74 & $19.50-76.96$ \\
\hline 4 & Asthana et $\mathrm{al}^{8}$ & $\begin{array}{l}\text { Systematic } \\
\text { review }\end{array}$ & SEAR & Oral cancer & SLT & 4.44 & - & $3.51-5.61$ \\
\hline 5 & Asthana et $\mathrm{al}^{8}$ & $\begin{array}{l}\text { Systematic } \\
\text { review }\end{array}$ & EMR & Oral cancer & $\overline{S L T}$ & 1.28 & - & $1.04-1.56$ \\
\hline 6 & Asthana et al ${ }^{8}$ & $\begin{array}{l}\text { Systematic } \\
\text { review }\end{array}$ & WHO (six) & Oral cancer & Gutkha & 8.67 & - & $3.59-20.93$ \\
\hline 7 & Asthana et al $\left.\right|^{8}$ & $\begin{array}{l}\text { Systematic } \\
\text { review }\end{array}$ & WHO (six) & Oral cancer & Pan masala & 7.18 & - & $5.48-9.41$ \\
\hline 8 & Asthana et al ${ }^{8}$ & $\begin{array}{l}\text { Systematic } \\
\text { review }\end{array}$ & WHO (six) & Oral cancer & Oral snuff & 4.18 & - & $2.37-7.38$ \\
\hline 9 & Asthana et $\mathrm{al}^{8}$ & $\begin{array}{l}\text { Systematic } \\
\text { review }\end{array}$ & WHO (six) & Oral cancer & Manipuri tobacco & 3.32 & - & $2.32-8.36$ \\
\hline 10 & Byhamre et $\mathrm{al}^{31}$ & Cohort & Sweden & Cancer & Snus & - & 1.12 & $1.00-1.26$ \\
\hline 11 & Khan et al ${ }^{12}$ & Case control & Pakistan & Oral cancer & Snuff & 4.82 & - & $2.37-9.80$ \\
\hline 12 & Khan et al ${ }^{12}$ & Case control & Pakistan & Oral cancer & Betel leaf & 4.42 & - & $1.66-11.91$ \\
\hline 13 & Byhamre et $\mathrm{al}^{31}$ & Cohort & Sweden & Cardiovascular & Snus & - & 1.27 & $1.15-1.41$ \\
\hline 14 & Gupta et al ${ }^{11}$ & $\begin{array}{l}\text { Systematic } \\
\text { review }\end{array}$ & WHO & CHD (fatal) & Snus & 1.1 & - & $1.00-1.20$ \\
\hline
\end{tabular}

Abbreviations: CHD, coronary heart disease; EMR, Eastern Mediterranean Region; HR, hazard ratio; OPMD, oral potentially malignant disease; OR, odds ratio; OSMF, oral submucous fibrosis; SEAR, South-East Asia Region; SLT, smokeless tobacco; WHO, World Health Organization.

According to National Cancer Registry Program of Indian Council of Medical Research at Bangalore in Karnataka, proportional increase in mouth cancer cases were significantly more in younger age group (third and fourth decades) as compared with fifth and second decades. This suspicious rise in the mouth cancers cases in the young cannot be sheer coincidence with the time period of popularization of gutkha and other factory-made tobacco products. This shows that time to carcinogenesis was significantly less in gutkha chewers as compared with loose tobacco product users, making such factory made tobacco product more dangerous than others, leading to development of cancer in young age.

\section{Smokeless Tobacco and Oral Potentially Malignant Disease}

Study published in the year 2020 which evaluated medical records of 1,007 individuals coming to the tertiary care center in the South India assessed the pattern of tobacco use and corresponding oral mucosal alteration. ${ }^{16}$ In this study, more than $50 \%$ were tobacco smokers and SLT user. About $18.2 \%$ of bidi smokers developed carcinoma and 15\% developed leukoplakia. Various forms of SLT are strongly associated with development of oral submucous fibrosis (OSMF). ${ }^{17}$ This study has shown that SLT including betel quid with tobacco and gutkha chewers lead to 18 times higher chances of development of OSMF as compared with those who do not chew SLT in any form. Oral submucous fibrosis is a systemic condition which leads to irreversible reduction in mouth opening. Onethird of all the betel quid tobacco and gutkha users developed tobacco pouch keratosis. The most important findings of the study were the combination of gutkha and bidi was even more lethal, leading to 12.3 times higher chances of oral cancer. Study conducted by Tata Memorial Hospital in Mumbai screened 12 slum clusters, consisting of approximately 11,000 tobacco chewing women. They found 327 (3.2\%) were screened positive and $75 \%$ of the screen-positive women had precancerous or cancerous lesion. ${ }^{18}$ Thus reaffirming the evidence that SLT users have a high incidence of precancerous lesion even in females. Another female-based study conducted in Bengal enrolled 155 women had high prevalence of SLT use (18.7\%). They also found that there was a significant association between SLT use and unhealthy oral mucosal changes. ${ }^{19}$ Another cross-sectional study conducted in Bhavnagar district of Gujarat concluded that every third of the population consumes SLT with majority being mawa and gutkha. This truly corresponds to high incidence of OSMF, OPMD (oral potentially malignant disease) and oral cancer in the South Gujarat. ${ }^{20}$ Another study analyzing the effect of SLT user in migrant construction site workers in Chennai has shown alarmingly higher rates of potentially malignant disorders in the oral cavity. Inflammatory mucosal lesions in the oral cavity were 70.97\% and more among SLT users compared with $22.58 \%$ among tobacco smokers and were significantly associated with up to 20 years of tobacco consumption. ${ }^{21}$ 


\section{Genetic and Molecular Studies: Preclinical Studies}

A study led by Datta et al aimed at assessing the microscopic and the phenotypic changes in the oesophageal human cell lines. ${ }^{22}$ In this study, oesophageal cell lines were treated with chewed tobacco for 8 months. They observed progressive increase in proliferative ability of cells and also increased invasive capabilities with increased duration of exposure to chewed tobacco. Last year, a study led by Pansare et al was also successful in identifying SLT-induced gingivobuccal carcinoma cell lines. ${ }^{23}$ Thus, suggesting SLT-induced oral mucosa changes had genetically altered cell lines. An in vitro study observing the effect of prenatal gutkha chewing on the adult liver has shown that prenatal exposure to gutkha followed by a high fat diet in adulthood significantly increased the chances of fatty liver in males. Maternal exposure of gutkha raises the cytokine levels including interleukin (IL)-1b and IL-6 and m-RNA collagen expression. These experimental findings conclude that gutkha has the potential to induce fatty liver changes in a gender-dependent manner. ${ }^{24}$

Another genetic study assessed the effect of a type of SLT (Maras) on the deregulation of micro RNA. They found that SLT also leads to deregulation of miR-200b and miR-92a expressions. Deregulation of micro RNAs mediate process of tumorigenesis, such as inflammation, cell cycle regulation, stress response, differentiation, apoptosis, and invasion consequently leading to carcinogenesis. ${ }^{25}$

\section{Smokeless Tobacco and Cardiovascular Diseases}

Apart from cancer, SLT-associated mortality due to heart disease contributed to 6 million DALYs and 258,000 lives were lost. A study analyzing cardiovascular risk among SLT users found to have significant association of SLT use and fatal coronary heart disease (CHD). ${ }^{11}$ A case control study analyzing the cardiovascular effects of SLT on young individuals recorded significantly higher systolic blood pressure, mean arterial pressure, heart rate, and other component of heart rate variability and these were significantly deranged in the group of individuals consuming SLT. Thus this study shows that SLT adversely affects the cardiovascular parameters increasing the risk of cardiovascular disease. ${ }^{26}$ Another study conducted on sub-Saharan women SLT user found higher differential blood pressure. ${ }^{27}$ Similarly, an Indian study evaluating the inflammatory and thrombotic markers in SLT user found significantly higher levels of IL-6, tumor necrosis factor (TNF)- $\alpha$, fibrinogen, and D-dimer. Higher inflammatory markers levels correspond with increased risk of thrombotic cardiovascular events among SLT users. ${ }^{28}$ Another cross-sectional study found total cholesterol, triglyceride (TG), and low-density lipoprotein cholesterol (LDLC) significantly higher in pan masala tobacco chewer. ${ }^{29}$ In a prospective Swedish study with a follow-up of 8 years found 1.5 times higher risk of ischemic and 1.6 times risk of total stroke in nonsmoking Snus user as compared with nonusers. ${ }^{30}$ A Swedish study analyzed the all-cause mortality of falsely promoted safe product so called Snus. ${ }^{31}$ This study stated that Snus leads to increased all-cause mortality (1.28 times higher) with higher cardiovascular mortality (1.27 times higher) and cancer mortality (1.1 times). Thus there is enough current evidence to prove that SLT use is associated with high cardiovascular risk.

\section{Smokeless Tobacco and Pregnancy}

A systematic review was conducted to find the potential effects of SLT consumed during pregnancy. A systematic review of 21 studies concluded that SLT user probably increases the chances of poor outcome in pregnancy. ${ }^{32}$ Studies have also shown that prenatal Snus (SLT) exposure is associated with higher systolic pressure and altered heart rate variability at 6 years of child's age. Another Australian study found that SLT (pituri) use is associated with possible complication like elevated glucose concentration which may lead to gestational diabetes. ${ }^{33}$ Thus according to the current literature, SLT can potentially influence adverse maternal outcomes.

\section{Recommendation}

We need to make research efforts to recognize the oral potentially malignant disorder and cancer risk according to the type, frequency, and duration of use of different type of SLT product. Current evidence highly recommends screening for high-risk individuals (SLT user) for prevention and early detection of oral potentially malignant lesion and oral cancer. It also recommends further research to find the direct association of cardiovascular disease and SLT use. Our review advocates screening pregnant women and creating awareness about the ill effects of SLT on postpregnancy adverse outcomes.

\section{Conclusion}

There is strong evidence to suggest that SLT increases the risk of oral potentially malignant disorder, oral cancer, and it is detrimental to oral health. Evidence also indicates that it worsens the risk of cardiovascular disease and adverse maternal outcomes including low birth weight and gestational diabetes.

Funding

This research did not receive any specific grant from funding agencies in the public, commercial, or not-forprofit sectors.

Conflict of Interest

None declared.

\section{References}

1 Sung H, Ferlay J, Siegel RL, et al. Global cancer statistics 2020: GLOBOCAN estimates of incidence and mortality worldwide for 36 cancers in 185 countries. CA Cancer J Clin 2021;71(03): 209-249

2 Singhavi HR, Singh A, Bhattacharjee A, Talole S, Dikshit R, Chaturvedi P. Alcohol and cancer risk: a systematic review and metaanalysis of prospective Indian studies. Indian J Public Health 2020;64(02):186-190

3 GBD 2017 Risk Factor Collaborators. Global, regional, and national comparative risk assessment of 84 behavioural, environmental and occupational, and metabolic risks or clusters of risks for 195 countries 
and territories, 1990-2017: a systematic analysis for the Global Burden of Disease Study. Lancet 2017;390(10100):1345-1422

4 Gupta S, Gupta R, Sinha DN, Mehrotra R. Relationship between type of smokeless tobacco \& risk of cancer: a systematic review. Indian J Med Res 2018;148(01):56-76

5 Gupta PC, Subramoney S. Smokeless tobacco use, birth weight, and gestational age: population based, prospective cohort study of 1217 women in Mumbai, India. BMJ 2004;328(7455):1538

6 Gupta PC, Ray CS, Narake SS, et al. Profile of dual tobacco users in India: an analysis from Global Adult Tobacco Survey, 2009-10. Indian J Cancer 2012;49(04):393-400

7 Kumar S. Indian state bans tobacco based chewing products. BMJ 2002;325(7357):184

8 Asthana S, Labani S, Kailash U, Sinha DN, Mehrotra R. Association of smokeless tobacco use and oral cancer: a systematic global review and meta-analysis. Nicotine Tob Res 2019;21(09):1162-1171

9 Asthana S, Vohra P, Labani S. Association of smokeless tobacco with oral cancer: a review of systematic reviews. Tob Prev Cessat 2019;5:34

10 Patil S, Alamir AWH, Arakeri G, et al. The relationship of shammah (Arabian snuff) chewing to the risk of oral cancer and oral potentially malignant disorders. J Oral Pathol Med 2019;48(06):425-432

11 Gupta R, Gupta S, Sharma S, Sinha DN, Mehrotra R. Risk of coronary heart disease among smokeless tobacco users: results of systematic review and meta-analysis of global data. Nicotine Tob Res 2019;21(01):25-31

12 Khan SZ, Farooq A, Masood M, et al. Smokeless tobacco use and risk of oral cavity cancer. Turk J Med Sci 2020;50(01):291-297

13 Bastakoti S, Shrestha G, Kumar Gautam D, et al. Clinico-pathological spectrum of oral cavity lesions at a tertiary care center in central nepal: a descriptive cross-sectional study. JNMA J Nepal Med Assoc 2021;59(234). Doi: 10.31729/jnma.5539

14 Sinha DN, Bajracharya B, Khadka BB, Rinchen S, Bhattad VB, Singh PK. Smokeless tobacco use in Nepal. Indian J Cancer 2012;49(04): 352-356

15 Pandey A, Singh A, Singh S, et al. Oral smokeless tobacco consumption pattern among rural Indian cancer patients: a prospective survey. South Asian J Cancer 2020;9(01):17-19

16 Khan A, Ongole R, Baptist J, Srikant N, Lukmani F. Patterns of tobacco use and its relation to oral precancers and cancers among individuals visiting a tertiary hospital in South India. J Contemp Dent Pract 2020;21(03):304-309

17 Rao NR, Villa A, More CB, Jayasinghe RD, Kerr AR, Johnson NW. Oral submucous fibrosis: a contemporary narrative review with a proposed inter-professional approach for an early diagnosis and clinical management. J Otolaryngol Head Neck Surg 2020;49(01):3

18 Mishra GA, Pimple SA, Gupta SD. Smokeless tobacco use and oral neoplasia among urban Indian women. Oral Dis 2019;25(07): 1724-1734

19 Bhattacharjee T, Mandal P, Gangopadhyay S. Smokeless tobacco use and related oral mucosal changes in Bengali Women. J Family Med Prim Care 2020;9(06):2741-2746
20 Rupani MP, Parikh KD, Kakadia MJ, Pathak MM, Patel MR, Shah MA. Cross-sectional study on smokeless tobacco use, awareness and expenditure in an urban slum of Bhavnagar, western India. Natl Med J India 2019;32(03):137-140

21 Tirukkovalluri SS, Luck CP, Makesh RLS, et al. Workplace based potentially malignant oral lesions screening among tobacco consuming migrant construction site workers in Chennai, South India: a pilot study. J Family Med Prim Care 2020;9(09): 5004-5009

22 Datta KK, Patil S, Patel K, et al. Chronic exposure to chewing tobacco induces metabolic reprogramming and cancer stem cell-like properties in esophageal epithelial cells. Cells 2019;8(09):949

23 Pansare K, Gardi N, Kamat S, et al. Establishment and genomic characterization of gingivobuccal carcinoma cell lines with smokeless tobacco associated genetic alterations and oncogenic PIK3CA mutation. Sci Rep 2019;9(01):8272

24 Doherty Lyons S, Blum JL, Hoffman-Budde C, et al. Prenatal exposure to gutkha, a globally relevant smokeless tobacco product, induces hepatic changes in adult mice. Int J Environ Res Public Health 2020;17(21):7895

25 Taş B, Güre AO. The effect of Maras powder and smoking on the microRNA deregulation of oral mucosa. J Appl Oral Sci 2020;28: e20190382

26 Choudhary AK, Qudeer A. Smokeless tobacco: risk factor for cardiovascular and breathing in young Indian adolescent. Hipertens Riesgo Vasc 2019;36(04):176-183

27 Diendéré J, Zeba AN, Nikièma L, et al. Smokeless tobacco use: its prevalence and relationships with dental symptoms, nutritional status and blood pressure among rural women in Burkina Faso. BMC Public Health 2020;20(01):579

28 Zutshi DV, Gupta MD, Girish MP, et al. Evaluation of systemic inflammatory and thrombotic markers of cardiovascular risk among young Indian oral tobacco users. Indian Heart J 2020;72 (05):389-393

29 Shrestha S, Mishra DR, Dhakal N, Bhandari S, Khanal S, Lamsal M. Correlation of urinary cotinine with cardiovascular risk factors in pan masala tobacco users. Indian Heart J 2019;71(06):459-463

30 Titova OE, Baron JA, Michaëlsson K, Larsson SC. Swedish snuff (snus) and risk of cardiovascular disease and mortality: prospective cohort study of middle-aged and older individuals. BMC Med 2021;19(01):111

31 Byhamre ML, Araghi M, Alfredsson L, et al. Swedish snus use is associated with mortality: a pooled analysis of eight prospective studies. Int J Epidemiol 2021;49(06):2041-2050

32 De Queiroz Andrade E, Da Silva Sena CR, Collison A, et al. Association between active tobacco use during pregnancy and infant respiratory health: a systematic review and meta-analysis. BMJ Open 2020;10(09):e037819

33 Ratsch A, Bogossian F, Steadman K. Central Australian Aboriginal women's pregnancy, labour and birth outcomes following maternal smokeless tobacco (pituri) use, cigarette use or no-tobacco use: a prospective cohort study. BMC Public Health 2021;21(01):814 